\title{
A EVOLUÇÃO DO INSTITUTO DA ARBITRAGEM COMO GARANTIA DE ACESSO À JUSTIÇA
}

\section{Bárbara Veras Gadelha}

Aluna do Curso de Direito da Universidade de Fortaleza.

barbara_gadelha@hotmail.com

Sumário: Introdução. 1. Referencial teórico: meios alternativos de solução de conflitos, análise: evolução histórica do instituto e arbitragem: conceitos e características. 2. Resultados: acesso à justiça $\mathrm{x}$ arbitragem, Lei 9.307/96: análises e perspectivas e a arbitragem e seus princípios básicos. Considerações finais.

Resumo: Os meios extrajudiciais de solução de conflitos têm surgido e se aperfeiçoado ao longo do tempo como forma de promover uma melhoria nas relações que necessitam da prestação da tutela jurisdicional. O instituto da arbitragem, oriundo de tempos remotos, ressurge no Brasil e no mundo, como uma possibilidade de viabilizar a solução de conflitos e diminuir os problemas que fazem referência ao princípio do acesso à justiça e ao Judiciário. Com o advento da Lei 9.307/96, conhecida como a Lei da Arbitragem, esse instituto tão importante deixa de figurar apenas em poucos artigos constitucionais para ganhar um novo e primordial espaço dentro do ordenamento jurídico brasileiro. São estabelecidos novos objetos a serem apreciados, sujeitos processuais com características diferenciadas, como o árbitro, e novos conceitos são estabelecidos na busca de um melhor entendimento e utilização do tema. O presente estudo foi realizado a partir de pesquisa bibliográfica e utilização de legislação e doutrina específicas para a matéria. Conclui-se que algumas discussões são esclarecidas e o interesse pelo instituto da arbitragem ganha destaque, de modo que as novas estatísticas demonstram que o mesmo poderá ser considerado como uma das alternativas que circundam a atual crise de demandas do Poder Judiciário no país.

Palavras-chave: Meios extrajudiciais de solução de conflitos. Arbitragem. Acesso à justiça. Lei 9.307/96.

\section{INTRODUÇÃO}

Os meios extrajudiciais de conflitos estão sendo difundidos cada vez mais, não somente no Brasil, mas em diversos países. Entre eles, a arbitragem tem se destacado e ocupado papel fundamental na consolidação de um novo parâmetro, nacional e internacional, na busca por soluções complementares ao Poder Judiciário, soluções essas capazes de dirimir litígios existentes de modo célere e eficaz.

O estudo tem por objetivo esclarecer a evolução ocorrida dentro do contexto histórico do instituto da arbitragem e realizar uma análise dos seus conceitos e inovações no âmbito do acesso à justiça. Teve sua formulação baseada em pesquisas bibliográficas, doutrinas especializadas e legislações a respeito do tema. 
O instituto possui uma longa história, em que sua importância não passava de meros artigos soltos no ordenamento jurídico. Portanto, era pouco difundido e aplicado em outras épocas. Essa realidade prevaleceu até o ano de 1996, quando foi promulgada a Lei da Arbitragem, considerada um marco de extrema relevância para seu desenvolvimento.

Seu surgimento traz novos conceitos básicos e sujeitos processuais envolvidos em uma relação de confiança e imparcialidade na tentativa de dirimir qualquer conflito existente. São introduzidas definições, como por exemplo: os sujeitos capazes de contratar, aqueles a quem a arbitragem se destina e a figura do árbitro com deveres e obrigações, semelhantes aos juízes de direito, dentro desse instituto inovador que busca garantir o acesso à justiça.

Não obstante, esse instituto não abandona princípios fundamentais do direito e gerais do processo, utilizando-se deles e revelando princípios agora específicos da arbitragem. Tal instituto passa a ser visto como uma forma de jurisdição, fora das vias estatais, sendo possível sempre que seu objeto tratar-se de direito patrimonial disponível.

Em face da atual crise do Poder Judiciário, o instituto ressurge na tentativa de solucionar conflitos mais simples, de forma informal e com total atendimento ao princípio da celeridade das decisões. Ele encontra algumas polêmicas e críticas a esse respeito, no entanto, com a análise dos dados numéricos, será possível a observação de resultados positivos na busca de alternativas viáveis ao atual entrave existente em relação à prestação da tutela jurisdicional exercida pelo Estado.

\section{Referencial Teórico: Meios Alternativos de Solução de Conflitos, Análise: Evolução Histórica do Instituto e Arbitragem: Conceitos e Características}

\subsection{Meios alternativos de solução de conflitos}

Como o próprio nome assim define, far-se-á uma breve análise dos métodos, dentre eles a arbitragem, que funcionam como uma opção ao descompasso encontrado atualmente dentro do Poder Judiciário brasileiro. Esses métodos tendem a ter sua denominação caracterizada como meios complementares, e não alternativos, de solução de conflitos. Isso ocorre devido ao fato de eles tenderem a figurar como opções quase principais de solução de conflitos, sendo, dessa forma, complementares à jurisdição estatal.

As formas de soluções podem ser agrupadas em três pequenos grupos que variam de acordo com sua forma e evolução no tempo. São elas: autotutela, autocomposição e heterocomposição.

A autotutela ou autodefesa figurava em outras épocas e era caracterizada pela imposição da conhecida "lei do mais forte", ou seja, não havia a participação de nenhum terceiro e se fundamentava basicamente no fato de uma das partes impor sua decisão à outra. Devido à sua clara ineficácia, predominou apenas em sociedades antigas, no entanto, de modo excepcional ainda é aceita pelo direito brasileiro, como por exemplo, nos casos definidos como legítima defesa.

A autocomposição ocorre por meio do diálogo entre as próprias partes que buscam um consenso, sem o emprego da força da autotutela. Os litigantes procuram a solução do conflito de forma bilateral, estando cada um preparado para a possibilidade de abrir mão de parte de seus interesses para dirimir o litígio. Pode ocorrer de três formas, inclusive permitindo a participação de terceiros. São elas: a mediação, a conciliação e a moderação. 
Seguindo uma linha de raciocínio um pouco diferente, surgiu a heterocomposição que tem como característica principal a figura de um terceiro, alheio ao conflito, que intervém e se torna titular do poder de decisão. A sua diferença essencial, quanto aos demais métodos, se configura no fato de as partes se tornarem agora obrigadas à decisão do terceiro, que, de forma imparcial, decide a lide. É o principal grupo de solução de conflitos utilizado na atualidade e tem como componentes o processo, a jurisdição estatal e o instituto de arbitragem. Guerra Filho, em sua Revista de Processo, se pronuncia sobre o tema da seguinte maneira:

Uma vez produzido o conflito de interesses ou litígio, a resolução pode surgir por obra dos próprios litigantes ou mediante a decisão de um terceiro, alheio à contenda. Dessa forma o conflito de interesses pode ser solucionado por métodos parciais ou imparciais. (FILHO, 2001, p. $271-277$ ).

Logo, conforme se observa com a análise da citação acima mencionada, existem diversos métodos de solução encontrados atualmente no ordenamento jurídico brasileiro, fato esse que abre uma grande diversidade e oportunidade de escolha àqueles que buscam fugir do "caos" estabelecido no Judiciário. Os procedimentos são vários, restando apenas às partes adequarem seus casos concretos àqueles que atendam da melhor maneira os seus interesses. Hoje, devido à popularidade dos meios extrajudiciais alternativos de solução de conflitos, diversos fatores e variações devem ser analisados antes de se escolher o meio que convenha às partes envolvidas no litígio.

Ademais, o Conselho Nacional de Justiça (CNJ), diante desse cenário, publicou a Resolução $\mathrm{n}^{\circ} 125$ em 29 de novembro de 2010, que tem como objetivo a busca por um tratamento aos conflitos existentes no Poder Judiciário, propondo diversos mecanismos de solução de conflitos, dentre eles a mediação e a conciliação.

\subsection{Análise: evolução histórica do instituto}

O instituto de arbitragem surge em razão dos diversos litígios existentes entre partes que procuram meios que venham facilitar o diálogo e que recebam a intervenção de um terceiro, chamado árbitro capaz de dirimir, de modo amigável, os conflitos a ele trazidos.

Ao contrário da ideia que se imagina, a arbitragem não é tão atual quanto parece. Constitui um dos métodos extrajudiciais de solução de conflitos mais antigos e aplicáveis em diversos países no mundo. A sua evolução histórica se inicia em tempos remotos, durante a história antiga, e é caracterizada por se tratar de um dos institutos pioneiros quando fazemos referência à utilização de um terceiro que intervém entre as partes na busca de soluções para os conflitos.

Em razão do tempo de sua existência, surge um questionamento acerca de sua anterioridade quando comparada à jurisdição do Estado. Nesse caso, observamos dois posicionamentos: o que afirma que surgiram de forma concomitante e aquele que defende a ideia de seu surgimento ter ocorrido anteriormente ao da jurisdição estatal.

A primeira parte da doutrina afirma que, por se tratar de ideias bastante antigas, não seria possível definir sua ordem cronológica, defendendo, desse modo, que ambas teriam surgido ao mesmo tempo. Em contrapartida e de forma majoritária, a segunda parte da doutrina afirma ser inconcebível a hipótese anterior, visto que os conflitos que fizeram surgir os meios de acabar com esses problemas já existiam em tempos em que não se utilizava a jurisdição estatal, pois não havia ainda a ideia de criação de um estado. Logo, é inegável que a arbitragem antecedeu a utilização da jurisdição estatal, mas o surgimento desta nada interferiu naquela. 
A arbitragem pode ser, então, observada desde aproximadamente 3000 a. C., época em que predominava ainda o período imperial, contudo, se prolongou em diversas épocas, até atualmente ser reconhecida como instituto utilizado de forma generalizada como método de solução de disputas, sendo adotada por quase todos os países do mundo. (ALEM, 2009).

No Brasil, a arbitragem está presente no ordenamento jurídico desde o período colonial. No entanto, naquela época não era tida como um instituto de relevante importância. Quando nos referimos à legislação de nosso País, observamos que, com exceção da Constituição da República dos Estados Unidos do Brasil promulgada em 1891, todas as demais Constituições Federais fizeram referência ao instituto da arbitragem, mesmo que em forma implícita. Ademais, essa menção ao referido instituto não ocorre somente nos textos constitucionais, mas inclusive sendo abordada em leis e regulamentos que embasaram diversos estudos relacionados ao tema. (CARMONA, 2009).

Até meados dos anos 1990, constatava-se que as decisões proferidas por tribunais arbitrais eram, em sua maioria, declaradas nulas, o que revela a fragilidade e a pouca aplicabilidade do instituto àquela época. O gráfico a seguir nos revela uma pequena ideia das modificações ocorridas dentro da arbitragem e demonstra em números sua melhor aceitação após o final da década de 90:

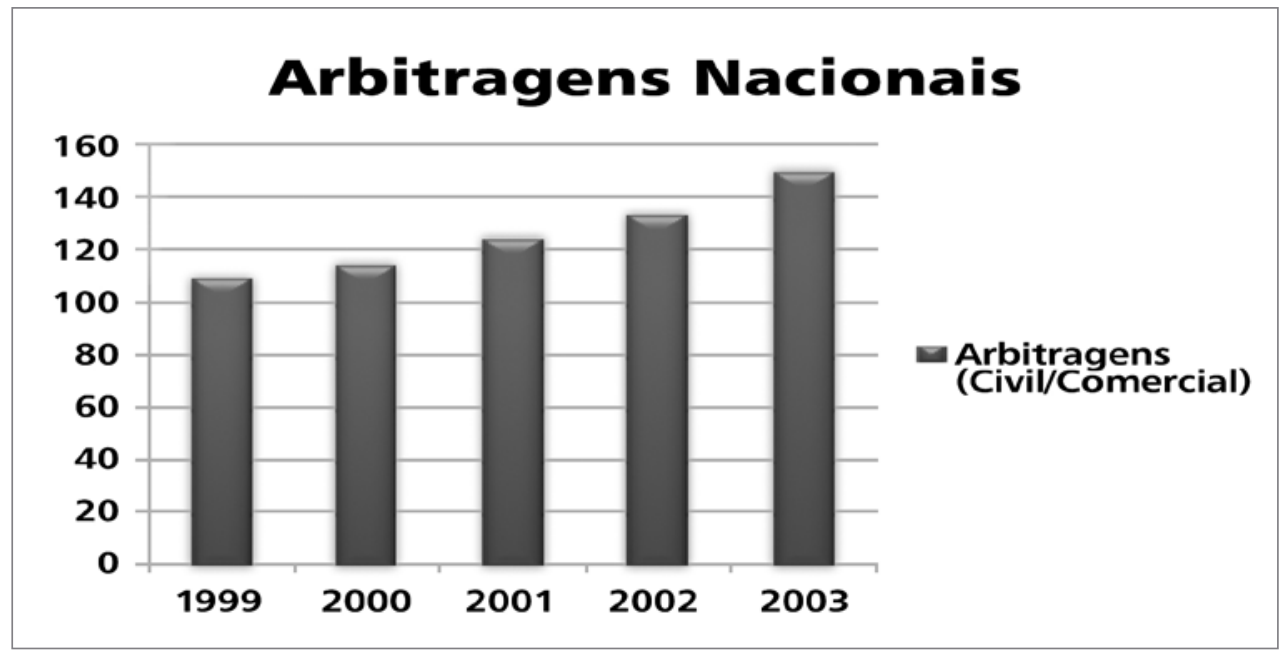

Figura 1. JÚNIOR, Gil Afonso de André. Arbitragem - breve comentário. São Paulo, 2013.

É a partir dessa observação que chega-se à conclusão de que a arbitragem, apesar de ter sua precisão estabelecida desde os primeiros ordenamentos brasileiros, nunca teve sua aplicação utilizada com tanta intensidade para a sociedade. Acredita-se que sua ineficácia se dava devido à sua falta de certeza e dificuldades encontradas quanto à sua aplicação. Partindo desse pressuposto, o legislador percebeu a necessidade de esclarecimentos a respeito desse instituto e, buscando torná-lo atuante de maneira coerente, em 23 de setembro de 1996, cria a Lei n ${ }^{\circ} 9.307$, atualmente chamada de Lei da Arbitragem e que representa um marco para sua evolução histórica.

\subsection{Arbitragem: conceitos e características}

Definir e caracterizar o meio de solução de conflitos chamado arbitragem, torna-se de extrema importância para seu estudo e entendimento. Por meio do conceito utilizado para apreciar 
a arbitragem é que adquire-se uma ideia ou noção de como a coisa é e de como ela vem a funcionar. Daí a importância da análise e avaliação dos diversos conceitos desse instituto que surgiram e se expandiram ao longo do tempo.

A arbitragem figura como um dos métodos alternativos de resolução de conflitos. Trata-se de uma opção mais simples e informal que aquela ofertada pelo Poder Judiciário e que tem como objetivo fundamental a busca e concretização de que trata o tão almejado princípio da celeridade das decisões, conforme determinado pela razoável duração do processo prevista pela EC 45/2004.

O instituto analisado constitui um meio de solução de conflitos realizado fora do Poder Judiciário, no entanto, que possui o condão de produzir seus mesmos efeitos. É considerado o meio mais utilizado de solução privada de litígios na atualidade. Segundo as palavras de José de Albuquerque Rocha sobre o tema:

[...] a arbitragem é forma de exercício da função jurisdicional do Estado por árbitros privados. Por outras palavras, a arbitragem é um sistema privado de resolução de litígios com o mesmo valor do Judiciário, que é o sistema estatal de resolução de conflitos. (2009, p. 88).

Essa equiparação do Poder Judiciário constitui uma das maiores diferenças existentes entre o instituto da arbitragem e os demais meios extrajudiciais de solução de conflitos, sendo eles: mediação (terceiro neutro intervém para aproximar as partes de modo que as elas cheguem a uma solução), conciliação (o terceiro que intervém realiza propostas, para que juntos cheguem à solução do litígio) e a negociação (as partes buscam o diálogo entre si, para sozinhas chegarem a uma solução).

O procedimento adotado por esse instituto se baseia na intervenção de uma ou mais pessoas, alheias ao conflito, conhecidas como árbitros, que recebem poderes do Estado. Esse árbitro deve ser de confiança das partes e escolhido por elas, sem qualquer intervenção estatal, que irão buscar a solução do conflito de forma consensual e amigável.

Outro fator de extrema relevância e que também distingue a arbitragem reside na característica impositiva de suas decisões. Na arbitragem não existe a parcialidade de uma solução. Esse instituto tem caráter facultativo, no entanto, uma vez adotado entre as partes, a decisão proferida pelo terceiro terá caráter obrigatório. Tal fator pode até distanciá-la dos demais meios, contudo, a aproxima da jurisdição exercida pelo Poder Judiciário, buscando decisões mais simples e sempre de modo imparcial. Nesse sentido, considera-se que a arbitragem seria como o exercício de jurisdição por autoridade não estatal.

\subsubsection{Objetos e sujeitos envolvidos na relação arbitral}

A prática da arbitragem, como todo instituto jurídico, impõe, àqueles que a utilizarem, os conhecimentos básicos das normas que devem ser observadas e seguidas. Desse entendimento é que verifica-se a necessidade de conhecer os objetos que engloba e os sujeitos que podem figurar em uma relação arbitral.

É inegável o crescimento alcançado pelo uso do instituto, no Brasil, como alternativa ao Poder Judiciário. No entanto, apesar de sua sedimentação em diversos setores, não raro encontra-se diversas outras matérias que poderiam apresentar excelentes resultados com esse método, mas que não o procuram muitas vezes apenas pela falta de conhecimento sobre os meios por ele utilizados. É exatamente o que observa-se no gráfico a seguir, que compara o uso da arbitragem nos processos trabalhistas e nos processos comerciais e civis. 


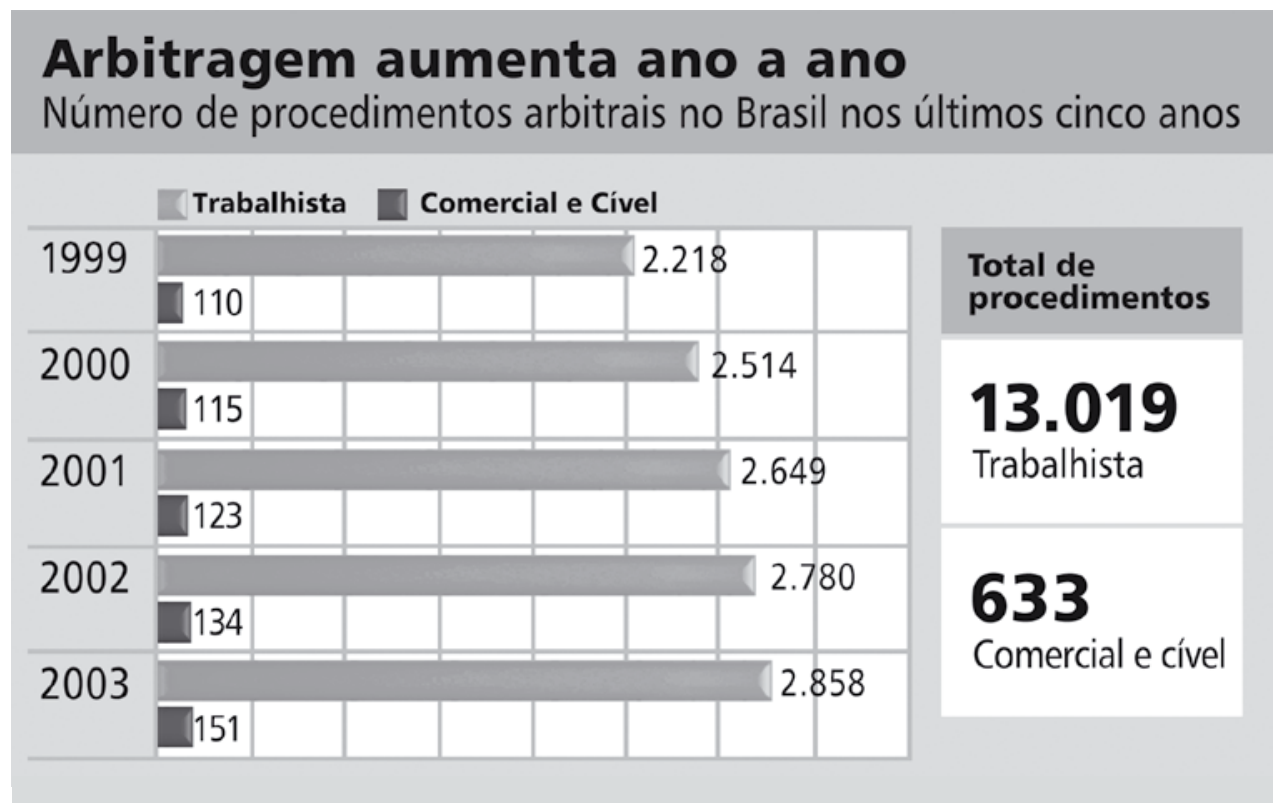

Figura 2. LEMES, Selma Ferreira. Contratos de Adesão e o Uso da Arbitragem. São Paulo, 2005.

Através dessa observação, faz-se necessário entender os interesses que podem ou não ser pleiteados em uma relação arbitral. Trata-se de um direito de natureza jurídica publicista. Apesar da ideia inicial, de considerar um acordo celebrado por vontade das partes, levantar a hipótese de ser um direito privado, deve-se observar que esse acordo irá produzir efeitos dentro da esfera do direito público. Portanto, apesar das duas correntes serem defendidas por doutrinadores, aquela que afirma ter natureza jurídica de direito público prevalecerá como doutrina majoritária e será adotada pelo legislador na lei da arbitragem. Com relação ao objeto do litígio, o artigo $1^{\circ}$ da Lei 9.307 define plenamente, conforme segue: "As pessoas capazes de contratar poderão valer-se da arbitragem para dirimir conflitos relativos a direitos patrimoniais disponíveis". Como se vê, a lei não abre nenhuma possibilidade de qualquer direito indisponível poder ser pleiteado diante de um tribunal arbitral.

A arbitragem pode ser aplicada em diversos ramos do direito - como direito do trabalho, direito do consumidor, direito empresarial -, desde que envolvam ações que tenham como objeto apenas direitos patrimoniais disponíveis, conforme expressa determinação legal. Conceituando direitos patrimoniais disponíveis e possíveis de se valerem da arbitragem, afirma Luiz Antônio Caetano:

Todos os direitos que têm conteúdo de ordem patrimonial ou econômica dos quais se pode dispor. Isto é, dar, usar, gozar, negociar, fornecer, comercializar, ceder, emprestar, e mesmo renunciar. Simplesmente todo ato ou fato entre as pessoas, firmas ou empresas particulares que possam ser objeto de qualquer contrato, seja por instrumentos particulares ou públicos, verbais, por cartas, e-mail etc. [...] (2002, p.17 e 57).

Portanto, a lei restringiu muito a abrangência, sendo arbitradas somente aquelas em que o Estado não cria uma proteção específica em virtude dos direitos fundamentais e da coletividade. Ademais, nos casos em que o juiz arbitral, no curso da solução, notar que se trata de direito indisponível, ela deverá ser remetida à apreciação pelo Poder Judiciário, conforme se depreende do art. 25 da Lei 9.307, que segue: 


\begin{abstract}
Art. 25. Sobrevindo no curso da arbitragem controvérsia acerca de direitos indisponíveis e verificando-se que de sua existência, ou não, dependerá o julgamento, o árbitro ou o tribunal arbitral remeterá as partes à autoridade competente do Poder Judiciário, suspendendo o procedimento arbitral. Parágrafo único. Resolvida a questão prejudicial e juntada aos autos a sentença ou acórdão transitado em julgado, terá normal seguimento a arbitragem.
\end{abstract}

Em relação aos sujeitos, a lei menciona apenas que podem valer-se da arbitragem as pessoas capazes de contratar. A capacidade é considerada o requisito essencial em todos os direitos e obrigações existentes dentro do ordenamento jurídico brasileiro, conforme afirma o Código Civil em seu art. 10. "toda pessoa é capaz de direitos e deveres na ordem civil."

No caso da capacidade imposta pelo instituto da arbitragem, é necessário que o sujeito seja plenamente capaz de dispor de seus direitos, não bastando apenas, como afirma o legislador, a capacidade de contratar. Desse modo, é necessário que a pessoa possa realizar o pleno exercício de seus direitos, sem qualquer limitação de capacidade, como por exemplo: idade, física ou psicológica. As limitações em relação a esses fatores se dividem em três grandes grupos essenciais, quando trata-se de pessoa natural, que delimitam a possibilidade ou não dos indivíduos adquirirem ou virem a adquirir capacidade jurídica. Os considerados absolutamente incapazes são aqueles menores de 16 anos ou que, por enfermidade ou doença mental, mesmo que transitória, não puderem exprimir sua vontade (art. $3^{\circ}$, Código Civil de 2002). Os que possuem capacidade relativa são aqueles que se encontram na faixa etária entre 16 e 18 anos, os viciados, os que apresentarem desenvolvimento mental incompleto e, enfim, os pródigos (art. 4 , Código Civil de 2002). Por fim, existem aqueles que são considerados como pessoas absolutamente capazes, por possuírem mais de 18 anos e não se encaixarem em nenhuma das demais características anteriormente mencionadas. Portanto, são passíveis de participar da arbitragem os que já atingiram a maioridade e que não se encaixem em nenhuma das causas de impedimento existentes.

Desse modo, podem figurar como partes na arbitragem as pessoas físicas ou jurídicas de direito público ou privado, desde que seus objetos não se relacionem com direitos indisponíveis e que se encontrem em total conformidade com os dispositivos legais.

\title{
1.3.2 O árbitro
}

Figurando como mais um sujeito dentro da relação de arbitragem, tem-se o árbitro que se diferencia das partes por assumir uma função e alguns poderes na busca da solução de algum conflito. $\mathrm{O}$ árbitro, assim como todos os demais que prestam serviços de natureza jurisdicional, deve seguir diversos deveres e obrigações. Ele possui função jurisdicional e difere do juiz de direito por não se exigir concurso público, e pelo fato de ter sua competência delimitada pela vontade estabelecida entre as partes e não por lei. O árbitro deve agir sempre de acordo com diversos institutos já estabelecidos, como: imparcialidade, competência e sigilo no desenvolvimento de suas atividades.

Exerce a função de pessoa responsável pelo correto procedimento da arbitragem, agindo sempre conforme os limites e parâmetros estabelecidos pela lei e seguindo as orientações e interesses das partes, de modo a evitar possíveis anulações que possam ocorrer.

Os requisitos para se tornar árbitro são bastante simples e basta que se trate de uma pessoa absolutamente capaz e que possua total confiança das partes, conforme artigo 13 da Lei 9.307/96. Não há a necessidade de realização de concurso para isso, bastando apenas que não haja restrições específicas referentes ao cargo exercido pela pessoa, a exemplo dos magistrados que não podem ser árbitro durante o exercício de suas atribuições. Com relação às causas de impedimento e suspeição, o artigo 14 da Lei 9.307/96 assim estabelece: 
Art. 14. Estão impedidos de funcionar como árbitros as pessoas que tenham, com as partes ou com o litígio que lhes for submetido, algumas das relações que caracterizam os casos de impedimento ou suspeição de juízes, aplicando-lhes, no que couber, os mesmos deveres e responsabilidades, conforme previsto no Código de Processo Civil.

Com isso, observa-se que o legislador impôs ao árbitro as mesmas condições estabelecidas pelo Código de Processo Civil, de modo a sujeitá-lo às mesmas regras impostas aos chamados juízes togadas, excepcionando apenas o fato de que no caso dos árbitros tais causas não ficam sujeitas a controle pelo Poder Judiciário.

\subsection{Tipos de arbitragem}

A arbitragem apresenta diversas classificações baseadas em diferentes características. Dentre elas, as mais relevantes são: voluntária ou obrigatória, de direito ou de equidade e $a d$ hoc ou institucional.

Quanto à iniciativa das partes, ela pode ser obrigatória, quando for imposta às partes, independentemente de sua vontade, o que difere do que ocorre no Brasil, onde somente se utiliza a arbitragem como caráter voluntário, em que as partes decidem se desejam ou não fazer uso da via arbitral.

Quanto à motivação das decisões, esta pode ser de direito, quando o árbitro se utiliza apenas de regras positivadas, e de equidade, quando o árbitro deve procurar adequar às circunstâncias do caso concreto e decidir sem ter como fundamento a utilização do direito positivo. Ambas são aceitas e utilizadas pelo sistema nacional.

Por fim, quanto às regras processuais adotadas, é possível que a arbitragem se divida em "ad hoc", quando elas são determinadas pelas partes litigantes, e "institucional", quando as regras são determinadas por uma instituição específica denominada como Tribunal Arbitral.

\section{Resultados: Acesso à Justiça X Arbitragem, Lei 9.307/96: Análises e Perspectivas e a Arbitragem e SeUs Princípios Básicos}

\subsection{Acesso à Justiça $x$ Arbitragem}

$\mathrm{O}$ acesso à justiça constitui um dos temas mais estudados e debatidos por diversos ramos do direito. Para alguns, caracteriza-se como um dever exercido pelo Estado na busca pela conquista da cidadania e efetivação da democracia. Outros acreditam ser uma das bases jurídicas do Estado, de modo a permitir que as pessoas possam buscar a reivindicação de seus direitos e solução de conflitos. É pleiteado como elemento básico dos Direitos Humanos e tem como objetivo a efetivação de direitos decorrentes à Justiça de acordo com cada caso concreto de forma equânime.

$\mathrm{O}$ acesso à justiça é considerado como princípio fundamental e procura garantir a possibilidade de que todos tenham acesso a órgãos dentro do Poder Judiciário para efetivar a proteção de seus direitos, conforme se observa com a leitura do artigo $5^{\circ}, \mathrm{XXXV}$, Constituição Federal de 1988:

Art. $5^{\circ}$. Todos são iguais perante a lei, sem distinção de qualquer natureza, garantindo-se aos brasileiros e aos estrangeiros residentes no País a inviolabilidade do direito à vida, à liberdade, à igualdade, à segurança e à propriedade, nos termos seguintes:

XXXV - a lei não excluirá da apreciação do Poder Judiciário lesão ou ameaça a direito.

Desde algumas décadas, essa prestação jurisdicional exercida pelo Estado tem, entretanto, enfrentado diversas barreiras na busca da efetivação de direitos. A partir do 
constitucionalismo houve uma tentativa de ampliação do acesso à justiça que acabou causando um grande entrave no sistema judicial brasileiro. Atualmente, considera-se que o Poder Judiciário está passando por uma crise de demandas, em que o cidadão figura como um personagem cada vez mais distante do verdadeiro acesso à justiça. A sociedade vem caracterizando a Justiça brasileira como portadora de diversos problemas de difíceis soluções, dentre os quais observa-se:

"[...] velha e antiquada, distante do povo, elitista, refletindo privilégios, não confiável, lenta, acomodada, cerceada, não acessível, não transparente, burocrática, não informatizada, desatualizada, ineficiente, desrespeitosa ao cidadão, instrumento eficaz de punição apenas contra os pobres [...]" (TEIXEIRA, 1994, p.117).

A opinião social acima demonstrada representa a infinidade de problemas enfrentados pela crise do Judiciário brasileiro. Diante disse, surge a necessidade de buscar novos institutos capazes de auxiliar no alcance do ideal de justiça.

A prestação da tutela jurisdicional e o consequente acesso à justiça são prestados majoritariamente pelo Poder Judiciário, mas nada obsta que se busque outras opções extrajudiciais adequadas a garantir a efetivação desse direito, como por exemplo, o uso da arbitragem.

Quando parte-se do pressuposto de eficácia, percebe-se que a Justiça brasileira encontra-se em desacordo com a atual realidade social. A demasiada busca pelo Judiciário, como único órgão de jurisdição, criou um desequilíbrio entre as necessidades da sociedade e a efetivação dos direitos. Daí entende-se o por quê dos meios extrajudiciais de conflitos voltarem a ganhar atenção, por se tratarem de uma possibilidade concreta de resolução de litígios que o Judiciário, no momento, encontra-se incapaz de resolver.

Diante de todos esses acontecimentos, o Judiciário brasileiro está abandonando a antiga visão de monopólio da jurisdição, de modo a tentar encontrar respostas para a insatisfação com ele. E é essa conscientização que tem levado à ampla aplicação do instituto da arbitragem como alternativa ao Judiciário.

A jurisdição arbitral é aquela exercida em paralelo pela estatal, que como já visto anteriormente, apesar de sua parte privada, possui os requisitos essenciais ao atendimento das necessidades de tutela jurisdicional. Dentro dessa visão, a arbitragem apresenta vantagens essenciais à melhoria na crise de demanda, dentre elas: a celeridade, o caráter de título extrajudicial, a irrecorribilidade e a obrigatoriedade da sentença.

A maior celeridade das decisões representa uma das grandes vantagens, quando comparada à extrema morosidade que se acompanha em busca da prolação de uma sentença definitiva dentro do Poder Judiciário.

A característica de título extrajudicial configura uma das grandes inovações trazidas pela Lei 9.307/96, ao desconsiderar que todas as sentenças arbitrais necessitem de homologação pelo judiciário e confere mais credibilidade ao instituto no País.

A irrecorribilidade pode ser considerada um dos fatores que auxiliam na celeridade, visto que impossibilita o recurso de decisão arbitral, evitando, assim, a longa espera que se observa quando há a interposição de recursos dentro das instâncias do Poder Judiciário.

Por fim, a obrigatoriedade da sentença que configura uma estabilidade e segurança às decisões dos tribunais arbitrais. Cabendo aos tribunais estatais apenas o controle sobre os requisitos formais exigidos pelo instituto, fato esse que, conforme se observa no gráfico a seguir, reduziu de maneira significativa a anulação das sentenças arbitrais, que impedem a celeridade e a eficácia do acesso à justiça: 


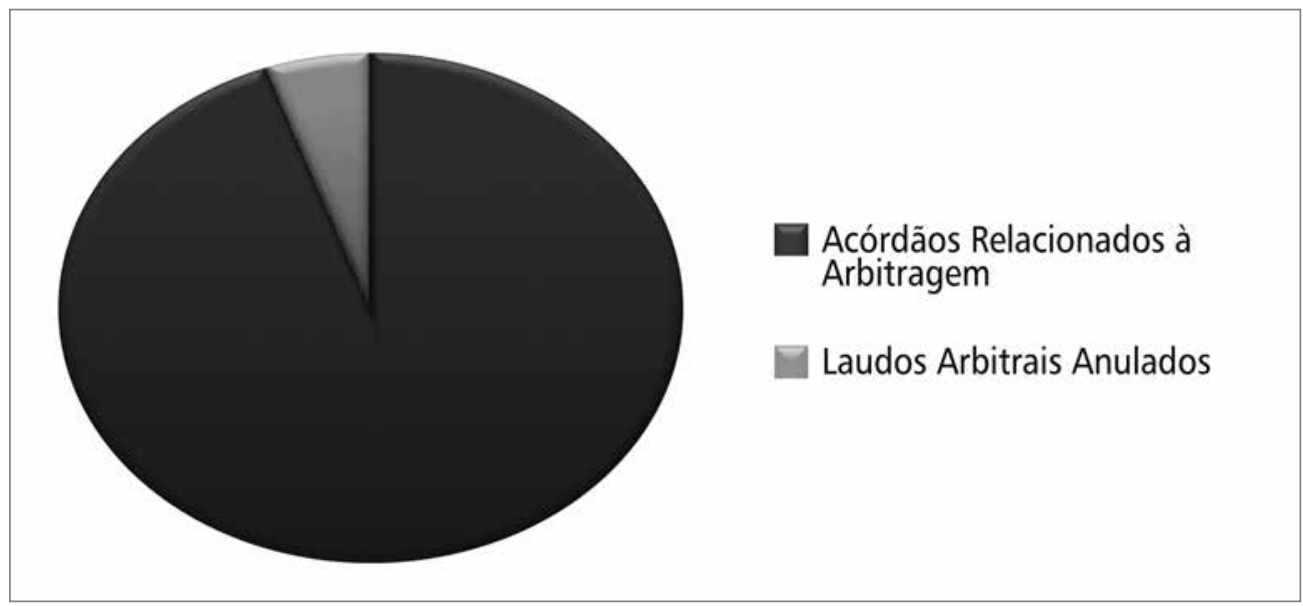

Figura 3. JÚNIOR, Gil Afonso de André. Arbitragem - breve comentário. São Paulo, 2013.

Portanto, o procedimento arbitral e demais meios extrajudiciais de conflitos existem e são medidas capazes de promover uma melhoria dentro do Judiciário brasileiro, restando apenas que sejam observadas todas as condições peculiares a cada caso concreto, de modo a viabilizar sua aplicação.

\subsection{Lei 9.307/96: análises e perspectivas}

A arbitragem para o direito brasileiro pode ser dividida em dois grandes momentos: antes e depois da criação da Lei 9.307/96 (Lei da Arbitragem). O instituto, que antes da lei não passava de meras previsões dentro do ordenamento e de pouquíssima aplicação prática, passa por acontecimento extremo e que lhe impulsiona a outro padrão no Brasil. A lei da arbitragem difunde por vários setores esse instituto, que havia ficado esquecido, e faz surgir a expectativa de uma solução.

Foram várias as tentativas de se criar um ordenamento específico para regular o instituo da arbitragem no Brasil e superar os obstáculos percebidos durante sua utilização. Foram três anteprojetos, durante os anos de 1981, 1987 e 1988, no entanto, que não passaram de tentativas na busca da tão necessária lei da arbitragem. (CARMONA, 2009).

Findados todos esses projetos, em 1991 surgiu o marco principal da evolução do direito arbitral: a operação Arbiter. Essa operação ocorreu após a observação de que a mudança deveria partir da sociedade e não de componentes do governo. Era necessário que o projeto fosse realizado com o intuito de atender às necessidades daqueles que realmente necessitavam de um meio alternativo confiável e eficaz de solução de conflitos. Foi então que com o apoio, sugestões e incorporações ao texto, o anteprojeto foi apresentado e aprovado. A diferença essencial se caracterizou pelo apoio buscado, não só no âmbito nacional como internacionalmente, e pelo cuidado para que seu texto não trouxesse qualquer inovação radical para o instituto. $\mathrm{O}$ trecho do parecer da Comissão de Constituição, Justiça e Cidadania que segue revela sua importância e seu diferencial:

[...] é fruto do estudo e empenho dos setores mais interessados da própria sociedade em levar adiante as novas ideias para a implantação de uma justiça, em sentido amplo, ágil, segura e técnica, além de pouco onerosa e informal. Para a elaboração do projeto, consultaram-se as mais modernas legislações sobre arbitragem e levaram-se em conta as diretrizes de organismos internacionais, dentre elas as fixadas pela ONU (Lei Modelo sobre Arbitragem 
Comercial, da Comissão das Nações Unidas para o Direito Comercial Internacional Unicitral), além das convenções de Nova Iorque (1958, não firmada pelo Brasil) e do Panamá (1975, firmada, mas, não ratificada pelo Brasil). (LIMA, 1994, p.105-106).

Trazendo diversas inovações e um embasamento jurídico diferenciador, surge a Lei da Arbitragem, composta por 7 capítulos e 44 artigos que deram uma nova roupagem e finalmente fizeram ressurgir o instituto da arbitragem, tornando-se um marco indispensável à sua consolidação.

\subsection{A arbitragem e seus princípios básicos}

Exatamente como ocorre com a maioria dos institutos adotados pelo sistema jurídico brasileiro, a arbitragem também consagra diversos princípios norteadores que se configuram com o objetivo de facilitar o seu entendimento e utilização por aqueles que assim desejarem. Aqueles que melhor caracterizam o instituto são os seguintes:

a) Princípio da inafastabilidade da prestação jurisdicional: inicialmente, observa-se que esse princípio é causador de diversas polêmicas existentes dentro da jurisdição arbitral. Com o surgimento do instituto da arbitragem se questionou a respeito da possibilidade de se afastar a prestação jurisdicional do Estado, visto que a decisão proferida pelo juízo arbitral possui caráter obrigatório e, uma vez as partes aderindo ao instituto, devem agir com total conformidade ao que for decidido durante a resolução dos conflitos.

Essa ideia fez surgir muitos estudos sobre o tema, até que chegou-se à conclusão de que o instituto da arbitragem não afasta o princípio da inafastabilidade da prestação jurisdicional. A decisão arbitral possui sim caráter obrigatório (só tem eficácia jurídica quando homologada), no entanto, o instituto da arbitragem é voluntário, fato esse que dá a opção aos litigantes de procurarem ou não a prestação jurisdicional exercida pelo estado. Logo, não há que se falar em afastabilidade da jurisdição.

O princípio se caracteriza como sendo a impossibilidade que qualquer conflito existente dentro do ambiente social tenha sua apreciação afastada do Poder Judiciário. Portanto, é assegurado às pessoas o devido acesso à prestação jurisdicional, com o objetivo de terem seus direitos assegurados e protegidos. Trata-se de mais um princípio explicitamente assegurado pelo dispositivo constitucional em seu artigo $5^{\circ}, \mathrm{XXXV}$.

b) Princípio do devido processo legal: ressalta o caráter jurisdicional da arbitragem ao estabelecer que, mesmo as partes podendo utilizar os procedimentos que lhes forem convenientes, há uma limitação a esse direito de escolha garantido por esse princípio. O direito pleiteado pelas partes não é suficiente, sendo necessário que para se atingir o que se pretende sejam observadas diversas regras que regulam o processo e garantem a proteção dos direitos fundamentais, exatamente como ocorre no órgão jurisdicional. Sua previsão ocorre de forma explícita na Constituição Federal de 1988 em seu artigo 5, LIV, conforme segue: “ninguém será privado da liberdade ou de seus bens sem o devido processo legal".

c) Princípio do livre convencimento motivado: se baseia especificamente no julgamento feito pelo juiz que o prende àquilo que se encontra dentro dos autos, vinculando os elementos que existem dentro do processo. O juiz aplica a lei de acordo com o caso concreto e, dessa forma, como elemento de formalidade existente no Judiciário, ele deve sempre motivar, fundamentar suas decisões. Assim, é necessário que não haja apenas a fundamentação legal de sua decisão, mas também argumentos e justificativas que deixem completamente esclarecido, para as partes e demais envolvidos no processo, o teor de suas decisões, sejam elas quais forem. Esse princípio encontra sua previsão legal na Constituição Federal de 1988 em seu artigo 93, IX, a seguir: 
Art. 93. Lei complementar, de iniciativa do Supremo Tribunal Federal, disporá sobre o Estatuto da Magistratura, observados os seguintes princípios:

IX todos os julgamentos dos órgãos do Poder Judiciário serão públicos, e fundamentadas todas as decisões, sob pena de nulidade, podendo a lei limitar a presença, em determinados atos, às próprias partes e a seus advogados, ou somente a estes, em casos nos quais a preservação do direito à intimidade do interessado no sigilo não prejudique o interesse público à informação.

d) Princípio da imparcialidade: esse princípio é tido como pressuposto de validade para todas as hipóteses em que se prevê a tomada de uma decisão, pelo juiz, dentro do ordenamento. Caracteriza-se como sendo a posição que deve ser adotada pelo juiz como equidistante das partes e alheia aos interesses por elas pleiteados. O juiz deve agir de modo a não influenciar as partes e sem permitir que as suas convicções pessoais venham a interferir em seu julgamento, de modo a comprometer a imparcialidade. Também é utilizado pela jurisdição estatal.

e) Princípio da autonomia da vontade: é considerado um dos pilares fundamentais do instituto da arbitragem, mas, ao mesmo tempo, o motivo de diversos questionamentos travados dentro do direito arbitral quando nos referimos à natureza jurídica da arbitragem. Conforme discutido anteriormente, a autonomia da vontade se caracteriza como sendo a parte privada existente dentro da natureza jurídica desse instituto.

Caracteriza-se pela ampla liberdade conferida às partes ao lhes proporcionar não só o direito de escolha, se querem ou não se submeter à arbitragem (arbitragem voluntária), mas inclusive o direito de escolha das regras e procedimentos, dentro das possibilidades legais, que devem ser adotadas na solução do conflito (arbitragem ad hoc);

f) Princípio da autonomia (cláusula compromissória): é um princípio específico do instituto da arbitragem e consiste no fato de desvincular as cláusulas compromissórias dos contratos que lhes deram origem, de sorte que elas permaneçam de modo independente e autônomo.

Consiste em uma exceção à regra de que o acessório segue o principal e impede que a cláusula compromissória seja atingida por ocasionais vícios de nulidade, invalidade ou inexistência provenientes do próprio contrato. Diferentemente de alguns princípios anteriormente citados, o princípio da autonomia da cláusula compromissória não encontra previsão legal no texto constitucional. Por se tratar de princípio caracterizador do próprio instituto, tem sua previsão legal estabelecida por lei específica, nesse caso, pela Lei da Arbitragem, no 9.307, artigo $8^{\circ}$, a seguir:

Art. $8^{\circ}$. A cláusula compromissória é autônoma em relação ao contrato em que estiver inserta, de tal sorte que a nulidade deste não implica, necessariamente, a nulidade da cláusula compromissória.

Parágrafo único. Caberá ao árbitro decidir de ofício, ou por provocação das partes, as questões acerca da existência, validade e eficácia da convenção de arbitragem e do contrato que contenha a cláusula compromissória.

Logo, são princípios fundamentais de direito e princípios gerais do processo que podem ser observados no âmbito da Constituição Federal ao tratar dos direitos e garantias fundamentais dos cidadãos. Contudo, também estão inseridos nesse rol exemplificativo princípios característicos do procedimento arbitral e que figuram como seus princípios básicos.

\section{Considerações Finais}

São diversos os meios extrajudiciais de disputas, dentre eles o instituto da arbitragem que, conforme observa-se, iniciou de forma tímida, sem qualquer alcance significativo dentro do 
direito brasileiro. No entanto, com a criação da Lei da Arbitragem, esta passa a ser vista como uma esperança ao entrave em que se encontra o atual Poder Judiciário.

São muitos os debates e as polêmicas a respeito do tema, mas isso não impossibilita que o instituto seja aplicado em concomitância com o órgão Judiciário na busca do efetivo acesso à justiça. O estudo revela que a arbitragem, a partir da promulgação da Lei 9.307 em 1996, trouxe diversos novos instrumentos capazes de promover uma segurança e confiabilidade para aqueles que dela se utilizarem. Trouxe consigo princípios inovadores e que promoveram novas observações dentro do antigo modelo de justiça existente, causando sua modernização e a consequente incorporação de ideias passíveis de atender aos interesses sociais.

A jurisdição privada invadiu certo espaço dentro da ordem jurídica brasileira, sendo indiscutível a importância que esse instituto conquistou e, de forma gradual, porém eficiente, vem adquirindo lugar de destaque na busca de proteção aos direitos e deveres dos indivíduos de nossa sociedade. A arbitragem tornou-se instrumento de extrema relevância quando nos referimos ao acesso à justiça, de modo que criou-se uma real expectativa de possibilidade de resolução do entrave atualmente existente no Judiciário do Brasil.

\section{REFERÊNCIAS}

ALEM, Fábio Pedro. Coleção Prática do Direito: Arbitragem. São Paulo: Saraiva, 2009.

ANDRÉ JÚNIOR, Gil Afonso de. Arbitragem - breve comentário. São Paulo, 2013. Disponível em: <http://www.floraecamargo.adv.br/2013/04/arbitragem-breve-conceito/>.

BONFIM, Ana Paula Rocha do. et. al. Dez Anos da Lei de Arbitragem: aspectos atuais e perspectivas para o instituto. Lumen Juris, 2007.

BORGES, Antônio de Moura. Perspectivas da Arbitragem no Brasil. 3. ed. Brasília. Disponível em: $<$ http://www.arcos.org.br/periodicos/revista-dos-estudantes-de-direito-da-unb/3aedicao/perspectivas-da-arbitragem-no-brasil/>.

BRASIL. Lei 9.307, de 23 de setembro de 1996. Dispõe sobre a Arbitragem. Diário Oficial da República Federativa do Brasil, Brasília.

BREVES Notas Sobre os Modos de Solução de Conflitos de Interesses. Revista de Processo. $\mathrm{n}^{\mathrm{o}} 42,2011$.

CAETANO, Luiz Antunes. Arbitragem e Mediação. São Paulo, 2002.

CARMONA, Carlos Alberto. Arbitragem e Processo: um comentário à Lei 9.307/96. 3. ed. São Paulo: Saraiva, 2009.

LEITE, Francisco Tarciso. Arbitragem, Mediação e Conciliação no Direito Privado Patrimonial Brasileiro: instrumentos jurídicos para a solução de conflitos na sociedade brasileira contemporânea. UNIFOR, 2008.

LEMES, Selma Ferreira. Contratos de Adesão e o Uso da Arbitragem. São Paulo, 2005. Disponível em: <www.taesp.com.br/noticias.htm $>$.

LIMA, Cláudio Vianna de. Arbitragem: a solução. São Paulo: Forense, 1994.

LIMA JÚNIOR, José Natan Bezerra. A Arbitragem em Face da Decadência do Poder Judiciário. Premius, 2002. 
MEDINA, Paulo Roberto de Gouvêa. Direito Processual Constitucional. 3. ed. São Paulo: Forense, 2006.

MÉLO, Francilene Lucena. Arbitragem Brasileira e Princípios Constitucionais. Campina Grande, 2001. 190 p. Dissertação (Mestrado em Direito). Universidade Federal do Ceará, Fortaleza, 2001.

PAROSKI, Mauro Vasni. Do Direito Fundamental de Acesso à Justiça. v. 10. Londrina: Scientia Iuris, 2006.

ROCHA, José de Albuquerque. Teoria Geral do Processo. 10. ed. São Paulo: Atlas, 2009.

SADDI, Jairo. Poder Judiciário: reforma ou ruptura? São Paulo. Disponível em: $<\underline{\text { http: } / / w w w . ~}$ dcomercio.com.br/especiais/outros/digesto/digesto_21 especial/05.htm>.

SILVA, Adriana dos Santos. Acesso à Justiça e Arbitragem: um caminho para a crise do Judiciário. Manole, 2005.

SILVA, Gustavo Pamplona. Arbitragem: aspectos gerais da Lei 9.307-96. São Paulo, 2012. Disponível em: $<$ http://www.egov.ufsc.br/portal/conteudo/arbitragem-aspectos-gerais-da$\underline{\text { lei-9307-96>. }}$.

\section{THE EVOLUTION OF ARBITRATION AS GUARANTEE OF ACCESS TO JUSTICE}

Abstract: The non-judicial means of resolving conflicts have arisen and been perfected over time as a way to promote and improve relations that need the court's protection. The concept of arbitration comes from ancient times and reappears in Brazil and the world, as a possibility to facilitate conflict resolution and reduce the problems that make reference to the principle of access to justice. This study was conducted from literature and use of legislation and doctrine specific to the matter. With the advent of Brazil's Law 9.307/96, known as the law of arbitration, the institute gains a new and vital space within the Brazilian legal system. New objects are set to be examined, procedural subjects with different characteristics, as the referee, and new concepts are set out in search of a better understanding and use of the theme.

Keywords: Non-judicial means of dispute resolution. Arbitration. Access to Justice. Law 9.307/96.

Data de recebimento: maio/2013 - Data de aprovação: jun/2013 